\title{
To buy or not buy? A review of affective priming in purchase decision
}

This article was published in the following Dove Press journal:

Neuroscience and Neuroeconomics

30 August 2012

Number of times this article has been viewed

\author{
Gabriel JC Mograbi' \\ Daniel C Mograbi ${ }^{2}$ \\ 'Department of Philosophy, \\ UFMT - Federal University of \\ Mato Grosso, Mato Grosso, Brazil; \\ ${ }^{2}$ Department of Psychology, Institute \\ of Psychiatry, King's College London, \\ London, UK
}

\begin{abstract}
The current paradigm of neuroeconomics goes beyond merely axiomatic models and contemplates the influence of psychological factors on economic decisions. Under this framework, the main aim of the current review is to address the influence of affective priming in purchase decision. For this purpose, we first summarize the affective priming literature, followed by a section concentrating on purchase-decision studies that show that this phenomenon is value-driven, going beyond the emotionless calculation of traditional utility models in microeconomics. Finally, both themes are connected by reviewing the available experiments investigating affective priming effects on economic and purchase decision. We discuss these findings within a framework that considers that humans, as biological entities, attribute salience to hedonic information, highlighting the value-driven nature of decision-making, especially purchase decisions.
\end{abstract}

Keywords: affective priming, decision-making, purchase decision, prospective theory

\section{Introduction}

\section{An integrative framework}

Early in the history of neurosciences, the computer was seen as the main metaphor for information processing in the brain. Mental activity was compared to the working of a software, the computation of a series of algorithms. At its most extreme form, cognitivism suggested that the physical structure of the brain was irrelevant to its activity. ${ }^{1}$ This approach was strongly embedded in a rationalist and functionalist perspective, and precluded the scientific exploration of topics such as emotion and consciousness.

The past few decades have witnessed a gradual change of perspective in the study of the brain. One of the main causes for this theoretical shift has been the increasing emphasis given to evolutionary explanations of cognition. By highlighting that our brains have a long evolutionary history, researchers have shown cognition to be constrained both by the brain's physical structure and the adaptive demands of the organism. One of the main contributions from this view is the notion that the human brain, as any biological entity, is value-driven.* Following this emphasis on biological factors, cognitive neuroscience started to investigate more vigorously the theme of emotional processes. This led to the formation of what became known as affective neuroscience.

Parallel to that paradigmatic shift in the history of neuroscience in general, the emergence of the field of neuroeconomics followed a similar emphasis on the notion of psychological value. In 2002, the psychologist and mathematician Daniel Kahneman
Correspondence: Gabriel JC Mograbi Department of Philosophy, Institute for Human and Social Sciences, UFMT - Federal University of Mato Grosso, 2367 Av Fernando Corrêa da Costa, Bairro Boa Esperança, Cuiabá, MT 78060-900, Brazil

Tel +55 6531658479

Fax +55 6536347600

Email gabriel.mograbi@gmail.com 
was awarded the Nobel Prize in Economics. In the first words of his speech he mentioned his collaboration with Amos Tversky and their exploration of intuitive beliefs and choices that led to the idea of bounded rationality. Then he summarizes the nature of his speech as follows:

This essay presents a current perspective on the three major topics of our joint work: heuristics of judgment, risky choice, and framing effects. In all three domains we studied intuitions - thoughts and preferences that come to mind quickly and without much reflection. ${ }^{2}$

Astonishingly, a psychologist and mathematician had been awarded the Nobel Prize in Economics not because he had established a new orthodox axiomatic model but due to the introduction of psychological factors to elucidate our bounded rationality. As the author stresses in the speech cited above, "intuitions - thoughts and preferences that come to mind quickly and without much reflection" were his main target of study. Naturally, since the late seventies, the current paradigm in neuroeconomics has confronted the simple axiomatic utility models in microeconomics because of those inaugural and groundbreaking works that have been modifying our understanding of how affective and intuitive factors indeed play a role in our choices and preferences.

This integrative framework encompassing emotion, biological value, and psychologically influenced decisionmaking paved the road for studies exploring the effect of affective priming in decision-making. Nevertheless, few studies have been published in this field, and in the next section we indicate other historical reasons that might have led to this theme having been put aside for many years.

\section{Historical anecdotes}

Affective priming in purchase decision is not a new subject. However, the field was stuck and stagnated for decades because of a controversy started in the late fifties. A little hint of this history helps to understand why not much progress was achieved at the time and highlights one of the reasons for a still scarce scientific production in that particular field.

In 1957, James McDonald Vicary, an advertising researcher, conducted a study with controversial results. Supposedly, primes of 1/3000th of a second duration (constituted by written sentences and flashed by a tachistoscope during a film screening) suggesting consumption of a soft drink brand and popcorn were able to increase purchase of such items. The advertising researchers reported that sales of Coca-Cola and popcorn were augmented by $18.1 \%$ and $57.7 \%$, respectively, in the movie theater convenience store. ${ }^{3}$ The Central Intelligence Agency (CIA) of the US, concerned with the attested efficiency of such a technique and with its dangerous capability, even held an investigation during the late fifties and produced a report called The Operational Potential of Subliminal Perception. The report, originally labeled as secret, was released to the public for the first time in 1994 as part of the CIA historical review program. The report is available on the CIA website and had its last update on August 3, 2011. ${ }^{4}$ In an interview in 1962, although he did not confess that the results were fraudulent, Vicary admitted that the data exposed was "too small to be meaningful" and that the whole experiment was a "gimmick" that was not successful. ${ }^{5}$

Vicary himself produced many papers (currently available in a repository held by the University of Connecticut) and a book on the subject turned into a best seller. ${ }^{6,7}$ In the early nineties, Rogers provided compelling evidence that Vicary's experiment was a fraud. ${ }^{8}$ The hoax itself and all the subsequent controversy around the fraudulent mechanism used by Vicary created not only misleading conceptions but an aversion towards the study of implicit processing and subliminal factors, especially in advertising and its influence on purchase.

This aversion was compounded by a general misconception by laypeople concerning the potential effects of subliminal stimuli. This was clear, for example, in a series of high-profile court cases in the US. For instance, British heavy-metal rock band Judas Priest was accused by the plaintiffs (aka Vance vs Judas Priest $)^{9}$ of inducing the suicide of two teenagers by hiding auditory messages in the album Stained Glass. The trial turned into a junk-science disputation on subliminal auditory stimuli efficacy, with both sides producing a plethora of technical witnesses. The plaintiffs accused the band of intentionally hiding the auditory message "Do it!" on the album. As nothing supraliminal in the album could be cited as an antecedent of "it" since any material would be protected by the First Amendment, the plaintiffs used the strategy to say that the subliminal message triggered an already existing tendency of their sons to suicide. Judas Priest members were acquitted on the grounds that the behavior of the teenagers could be explained without any reference to subliminal messages. The judge, not being an authority on psychology, also concluded that subliminal messages were not so relevantly effective: "The strongest evidence presented at the trial showed no behavioral effects other than anxiety, distress or tension" ( $p$ 31). ${ }^{9}$ A similar case happened some months before the end 
of the Judas Priest trial, in which another American teenager committed suicide while listening to "Suicide Solution," a song by Ozzy Osbourne. The teenager's family claimed that subliminal messages present in the song had influenced his decision to commit suicide. Osbourne was summarily acquitted as the plaintiffs were not able to show any subliminal message present in the song. ${ }^{9}$

In the last few decades, after the rebirth of affective priming studies within a reliable scientific context, various types of scientific protocols and controlled testing have produced a great amount of evidence in this field. Overcoming the negative bias from previous decades, the first reliable scientific evidence on affective priming in financial decisions, especially purchase decisions, has been produced. We will analyze these very new and important few studies that address affective priming in purchase decision.

\section{Aim and structure of the review}

Considering the aforementioned framework, the aim of the current review is to show how decision-making (particularly, purchase decision) is influenced by automatic processing of emotional information. For this purpose, the current paper is divided as follows:

1. In the second section, we review the affective priming literature. We define this phenomenon, discuss potential mechanisms and neural correlates, and review studies that show that it can occur across modalities and even with longer time intervals between prime and target. We indicate that priming is an automatic and implicit processing of information that can influence subsequent judgment and behavior.

2. In the third section, we review papers showing that psychological factors have a considerable effect in various types of purchase decision and that merely axiomatic utility models would not be able to explain some complex affective influences on decisional processes, especially purchase decision.

3. In the fourth section, we then focus on the relationship between these two fields, reviewing evidence produced on the effects of affective priming in financial decisions. For this purpose, we performed a systematic search of articles in the PubMed database. Key words used were "affective priming," "decision-making," and "purchase decision," along with word variations (eg, "emotional" instead of "affective") and truncations when possible (eg, "affect\$," “prim\$”).

4. In the conclusion, we summarize the evidence and discuss its ethical implications.

\section{Affective priming}

Priming has been defined as an implicit memory process in which previous exposure to a stimulus influences the response to a subsequent stimulus. ${ }^{10}$ Priming is thought to be an implicit process in the sense that subjects are not aware of the relationship between prime and target, but nevertheless show performance biases that indicate that features of this relationship are processed at some level. ${ }^{11}$ A common misunderstanding is the notion that priming effects can only be obtained employing subliminal stimuli. In fact, this phenomenon has also been shown to occur when presenting explicit information; for example, in the case of amnesic patients ${ }^{10}$ or when asking subjects to pay attention to certain features of stimuli. ${ }^{12}$ Participants may show faster reaction time when responding to a primed item or form implicit conceptual associations, but without the correlational abilities provided by awareness, they lack the ability to manipulate the information in relation to other contextual knowledge. ${ }^{11,13}$

It has been shown that this implicit processing of information extends to the emotional content of stimuli, and that exposure to affective content impacts later judgment of emotional properties of objects. This phenomenon has been called emotional or affective priming. Usually, in affective priming paradigms, subjects have to judge the emotional content of a target stimulus after being exposed to a related or unrelated affective prime. The prime is typically but not always presented subliminally or masked, and its effects are inferred from interference effects in the response to the target stimulus. Interference effects can be measured in number of errors, ${ }^{14}$ latency to respond, ${ }^{15}$ or as a processing bias. ${ }^{16}$ In the latter case, the prime shifts evaluation of the target (eg, a neutral face) towards its affective content (eg, a negative emotion, such as sadness). Number of errors and latency to respond may be differentially affected according to the congruency between prime and target, with related primes decreasing time and errors and unrelated primes causing the opposite effect.

\section{Psychological factors in affective priming}

Early priming studies employed paired words presented within a short interval, and found that evaluation of targetword valence was influenced by the connotation of the prime. For example, in the seminal work by Fazio and colleagues, ${ }^{12}$ participants made a valence judgment (ie, whether a word such as "disgusting" was good or bad) after being exposed to a congruent or incongruent prime (eg, cockroach); latency to respond decreased when prime and target were congruent. 
Although studies traditionally suggested that affective priming occurs only within a short stimulus-onset asynchrony (the time interval between prime and target), recent evidence has indicated that even after long delays, primed affect may influence subsequent evaluations. For instance, Yang and colleagues found that fearful/neutral judgments in facial expressions were influenced by emotional faces presented subliminally 3 minutes before the target. ${ }^{17}$ In a similar vein, Baumgarter and Wirth reported how reading a newspaper article with emotional content led to participants recalling more valence-congruent information from six subsequent news articles. ${ }^{18}$

In addition to showing longer-lasting effects of primes, the original paradigm employed by Fazio et al ${ }^{12}$ has been expanded to a number of different directions. For example, even though early accounts suggested that affective primes would have an impact based only on their valence (ie, whether the content was positive or negative, regardless of specific emotions), there is evidence now that implicit affective processing can be highly specific, facilitating categorisation of emotion in target faces according to the particular emotion elicited in the prime (eg, fear, sadness, anger), beyond a simple valence-based judgment. ${ }^{19,20}$ Affective priming has also been shown to occur across sensory modalities. For instance, it has been shown that odors may prime target words that are affectively congruent. ${ }^{21} \mathrm{Li}$ et al replicated this phenomenon, showing that participants' ratings of likability of neutral faces were influenced by odors presented below detection thresholds. ${ }^{22}$ Another study found that affective music and speech prosody could affect judgment of valence of visual words with emotional connotations, and vice versa. ${ }^{23}$ A different study found only a facilitation effect in a crossmodal affective priming paradigm using auditory primes and visual targets with negative primes. ${ }^{24}$

Affective priming may also involve complex behavioral change. For example, in a recent study, Wyer and Calvini exposed participants subliminally to pictures of a group stereotyped as dangerous ("hoodies" to a UK sample) and tested social avoidance. ${ }^{25}$ After exposure to the prime, participants had to place their chairs close to an empty chair of an unknown who would soon arrive to work with them on a task. Seating distance was significantly farther away after priming with a picture of a person dressed up as a "hoodie" relative to exposure to a neutral picture of the same person.

Different mechanisms for priming effects have been suggested. One potential explanation is spreading of activation caused by the prime to related networks. ${ }^{26}$ The notion of spreading activation has been invoked to explain semantic priming, and assumes that concepts are organized based on semantic relatedness or proximity. According to this view, activation of one concept, eg, by reading a word cue, would spread more strongly to semantically related concepts than to unrelated concepts. The fact that strength of association between prime and target may modulate affective priming phenomena lends support for this notion, but evidence in this area has not been consistent. ${ }^{27,28}$ An alternative account suggests that priming is caused by response facilitation/competition, ie, previous exposure to the prime preparing the individual to respond in a certain way. ${ }^{27}$ This may involve a mechanism similar to the one found in Stroop paradigms, in which reaction time of subjects is measured for naming of words in a congruent vs incongruent condition (eg, naming a color for which the ink color and the word refer to the same color vs when the ink color and word differ). The Stroop paradigm suggests an interference effect which occurs at preattentive levels, providing a potential explanation for findings from a number of studies indicating interference in evaluative processes in affective priming. ${ }^{27}$ It is also in accordance with evidence indicating that attention and cognitive activity may reduce affective priming effects..$^{28}$

Whatever the case may be, consistent evidence indicates that exposure to the prime elicits automatic activation, which influences posterior tasks. In agreement with that, priming effects are stronger when primes are shortly followed by target. ${ }^{27,29}$ Further support for the notion that affective priming relies on automatic activation comes from studies employing successfully subliminal or masked primes; ${ }^{30}$ the fact that affect-laden primes can be processed without awareness suggests that priming occurs at preattentive levels. Automatic evaluative processes have to be understood within an evolutionary perspective. Quick processing of information allows prompt action in the environment, influencing survival chances. In this sense, automatic processing of affective objects could be considered, essentially, processing of value..$^{27}$

\section{Neural correlates of affective priming}

The neural correlates of affective priming have been explored in a few studies, and as expected, the pattern of activation depends on stimulus type and study design. Nevertheless, there is some evidence pointing to a consistent involvement of subcortical structures across affective priming paradigms. For example, studies using functional magnetic resonance imaging indicated increased activation in the amygdala in response to affective faces employed as primes, with a significant correlation between amygdala responses 
and prime effectiveness. ${ }^{31,32}$ Using magnetoencephalography, Garolera and colleagues found intensified responsiveness in the left amygdala for positive and negative word primes. ${ }^{33}$ Automatic amygdala responses to facial primes have also been shown in clinical populations such as psychosis, although with abnormal (hyperactive) response patterns. ${ }^{34}$ In addition to the amygdala, other neuroanatomical structures have also been implicated in affective priming, such as the left fusiform gyrus and insula..$^{35,36}$

These findings suggest a potential association between activations in subcortical brain areas and automatic processing of affective information. Further evidence for this notion comes from the study of "affective blindsight," the ability of "blindsight" patients (ie, patients who have suffered damage to V1 and are unaware of any perception in a certain area of their visual field) to categorize and respond to emotionally salient visual stimuli, such as facial expressions of emotion, presented in their blind field. ${ }^{37,38} \mathrm{~A}$ series of studies has indicated that "affective blindsight" relies on activations in subcortical visual pathways, including structures such as the amygdala, pulvinar nucleus, and superior colliculus. ${ }^{37-39}$

These findings can be integrated in a putative framework to explain automatic affective processing that bypasses awareness. Theoretical models based on animal fear processing suggest that information can either be transmitted through a quick, "dirty" road from the sensory organs to the thalamus and then to the amygdala, causing an automatic response, or via a slower road including cortical input and leading to awareness of fear. ${ }^{40}$ Given that the brain has multiple networks for processing of similar information, typical processing of affective information in humans simultaneously activates both networks, but in the absence of awareness, automatic processing of information via subcortical routes may lead to physiological responses and behavioral adaptation. ${ }^{41,10} \mathrm{As}$ mentioned above, the ability to respond quickly to environmental cues is crucial from an evolutionary point of view, and automatic processing of affective stimuli highlights the pervasive role of value in perception. As biological entities, humans are constantly screening their environment through value-based spectacles, and objects with hedonic relevance are endowed with increased salience.

It is possible that subcortical responses to affective primes may be modulated by cortical structures, such as the ventral prefrontal cortex (PFC). ${ }^{32}$ In a study using transcranial magnetic stimulation, Mattavelli et al "knocked out" the medial PFC (mPFC), which led to a disruption of the priming effect. ${ }^{42}$ However, in this study, participants were exposed to an unmasked prime for 250 milliseconds, so it is plausible to suggest that results reflected a disruption of less automatic and more elaborate evaluation process. Other cortical regions, such as the orbitofrontal cortex, have also been implicated in modulation of emotion and may mediate less automatic affective priming effects. ${ }^{43}$

\section{A framework for studying purchase decision}

Decision-making is an intricate and complex process present throughout human action, and every day we are faced with the constant necessity of deciding whether or not to take a course of action or to choose between options. Here we will focus only on economic decision-making in order to isolate purchase as our primary target. In a society based on consumerism, one of our contemporary dilemmas is to buy or not to buy. Another one is which goods deserve to be bought or not. Understanding such a context depends on illuminating the relationship between decision neuroscience and neuroeconomics. Or better, how economic choice and purchase decision are related in an individual. Most of the literature that treats economic choice in decision neuroscience takes, as a standpoint, microeconomic theories revised by experimental approaches on economic decision in neuroscience. Understanding the revision of standard microeconomics by the insertion of psychological value would help to elucidate the final section of this article, in which the effect of affective priming in purchase decision is considered. Another important consideration is that the traditional veridical decision-making approach that has one unique answer as correct, independently of subjective internal criteria, is not able to explain economic decisionmaking or purchase decision. An adaptive decision-making approach is necessary, as it contemplates subjective criteria that are indeed part of hedonic evaluations of our decisional processes. Adaptive decision-making depends on the needs or motivations of an organism, and economic choice is mostly based on the confrontations of those hedonic criteria with monetary prices and costs. ${ }^{44,45}$

\section{Psychological factors in purchase decision}

In past decades, Daniel Kahneman and Amos Tversky, among other psychologists, were able to challenge the grounds of utility theories by a series of experiments that started to overlap judgment and decision-making with choice theory. ${ }^{46}$ The classical utility theories grounded in axiomatic microeconomic models had to be revised in the light of many experimental discoveries in the field of neuroscience that were more sensible to psychological factors of human choice. One idea completely 
insensible to psychological aspects of decision-making assumed by classical utility theory as a central but implicit axiom was "description invariance," the notion that the way objects are described does not influence the choices among them. The influence of "framing" was a powerful counterexample demonstrated by experimental approaches. ${ }^{47}$ The way products are shown and described does influence their consumption. Following the same thread, Prelec and Loewenstein defended what they call a "double-entry" mental accounting theory based on the interaction of pleasure of consumption and displeasure of payment and debt. ${ }^{48}$ Thus in every purchase or consumption situation, instead of a purely rational Homo economicus, we have an individual guided by the tension of weighing the cost and pleasure. The saliency of cost turns into a negative affective valence and can indeed diminish pleasure. This idea is consistent with various theoretical accounts and experimental designs. ${ }^{48-51}$

In these hybrid accounts (which consider both hedonic and economic values and not only econometric axiomatic models), purchases are results of a combination of consumers' preference and price. ${ }^{48-50,52}$ Thus, the theoretical approach in which all these arguments and experiments are based on is centered in individuals' decisions guided by an interaction of economic and hedonic criteria. A careful analysis of these experiments, which are designed to study economic choice, shows that individual choice is, roughly speaking, modulated by (at least) two competing psychological aspects: the immediate pleasure of buying a product and the opposite and concomitant displeasure of paying for it. ${ }^{48,52}$

Considering the relationship between some temporal and affective factors, Prelec and Loewenstein suggest an example of an economic purchase: buying a reasonably expensive sports car by getting an auto loan. ${ }^{48}$ In a given moment, the subject, guided by the displeasure of dealing with the multiple installments, decides to pay off the whole debt. Financing costs are usually understood by the traditional axiomatic models as a form of temporally minimizing investment, ie, keeping resources for future consumption. Nevertheless, the authors argue that psychological factors such as "debt aversion" can influence decisions beyond the merely optimized economic best choice. Traditionally, microeconomic accounts state that the decision to purchase a good by a loan is based on the fact that the discounted present value of the utility stream exceeds the discounted present value of loan cost. However, this study suggests that affective factors can influence a debt payoff, showing that such a decision is taken to minimize displeasure even if it is not the optimal economic decision.
The two central assumptions of the "double-entry" mental accounting theory are prospective accounting and coupling. ${ }^{48}$ The first is a temporal-psychological factor that eludes the cost of a benefit. If a benefit is already paid in advance, its fruition is augmented, as it is taken by the consumer as if it were "free". If prepaid, the pleasure promoted by a vacation trip is augmented. If you have to pay for it after consumption, the displeasure is more salient. Coupling is defined as the degree to which consumption is associated to thoughts of payment and vice versa.

Credit card payment is one of the powerful phenomena within decoupling and must be taken as a strategy that creates the illusion of "costless" purchases by diminishing the saliency of payment, and thus its negative psychological factor. ${ }^{49}$ Buying with plastic seems to be less salient that taking the bills out of your wallet, counting them, and handing them to the seller. The experiment is able to show that even if a credit card payment has, economically speaking, the same or a considerably higher economic cost than paying in cash (and that excludes liquidity as a factor for decision), the simple fact that it is less salient to pay by credit than to pay in cash makes the purchaser less aware and thus less cautious (diminishes the arousal of negative valence) of what he is doing. Diminishing salience of payment elicits diminution of the concomitant displeasure (psychological negative value) of it and can make people take decisions that are highly counterproductive to their own economic balances.

The findings reviewed in this section indicate that decision-making can be driven by psychological or affective factors that cannot be explained within the traditional axiomatic optimized models. Rather, decision-making must be understood in an integrative framework such as the one we are suggesting here, in which affective factors and the organism's interests and values are not dissociable from cognition.

\section{Neural correlates of purchase decision}

Positive and negative affects evoked by anticipating gain and loss have been show to correlate with distinct neural circuits. ${ }^{50-58}$ As is also shown in the aforementioned experiments, the nucleus accumbens, an area associated with anticipating monetary gain, is consistently correlated with positive affective evaluation of items. Some of these studies were able to show that this positive affect is correlated with risk-taking and product preference. ${ }^{50,51}$ Montague and colleagues state that $\mathrm{mPFC}$ activation often reflects a prospective valuation of predicted reward in various different contexts. ${ }^{59}$ In a study by Piech and coworkers, the authors 
were able to show that $\mathrm{mPFC}$ plays a role in modulating more basic affective stimuli by its representation. ${ }^{60}$

By contrast, insula activation, associated with anticipating loss, has been consistently correlated with expensive prices. ${ }^{51,56,61}$ Expensive prices have also been shown to lead to deactivation of mPFC. ${ }^{51}$ The authors of the latter study were even able to make predictions of participants' purchases based on those circuits' activations. They stated that the nucleus accumbens and mPFC activations, usually associated with gain, serve as a predictor for purchase and that, instead, activation of the insula and deactivation of mPFC serve as a predictor of avoidance of purchase. Surely other brain areas are fundamentally involved in decision-making, but here we are only focusing on the more determinant dissociable areas that can be seen as neural predictors of whether a subject will engage in a purchase or not.

Altogether, studies reviewed in this section highlight that traditional axiomatic microeconomic models must be reconsidered in the light of psychological factors. If psychological factors can influence economic and purchase decision by their own natural processing, it is highly probable that manipulation of these factors could be profoundly effective in eliciting the prospected effects wanted by those people interested in influencing consumers' decisions. This is approached in the next section, where we review studies investigating the influence of affective priming on purchase decision.

\section{Affective priming in purchase decision}

If, as reviewed in the previous sections, decision-making is value-driven and perception is hardwired for the automatic appraisal of affective/emotional objects, it is plausible to suggest that exposure to such objects may influence financial decision-making. Even though very few studies have been conducted within this field, preliminary evidence suggests this may indeed be the case. For example, emotional context has been known to mediate perception of risk; Porcelli and Delgado report how acute stress influences risk-taking behavior, and Lerner and colleagues indicate that different negative emotions dissociate in their relationship with risk aversion, with anger leading to risk-seeking while fear induces risk-aversive behavior. ${ }^{62,63}$ In a related field, there is evidence that adoption of cognitive or affect-based strategies and thinking modes impacts on financial decision-making, with studies suggesting that donations and decision on how much to pay for something may be influenced by a less emotional/more analytical thinking style. ${ }^{64,65}$
Specifically on the subject of affective priming and purchasing decisions, very few studies have been conducted so far. Steffen and colleagues investigated the influence of affective primes (angry or happy facial expressions) in decision to rent an apartment, in an adaptation of the Go/No-Go paradigm. ${ }^{66}$ Participants were exposed to masked primes for 200 milliseconds (except for a no-prime condition during which nothing happened at that stage), followed by pictures of apartments with prices, after which they had to decide whether they would rent it or not. In addition to measuring reaction times, the study employed electroencephalography to investigate event-related potentials, in particular the N200, which is associated with certainty in decision-making. ${ }^{67}$ Results indicated an advantage of exposure to prime relative to the no-prime condition in terms of faster reaction times, but with no significant differences between happy and angry primes. However, a major limitation of this study was the absence of a control condition with neutral facial expressions; it is possible that faster reaction times with primes just reflected a general effect of facial-expression processing, irrespective of affective valence of stimuli. Nevertheless, differences between emotions were found for N200 peak amplitude, with larger peak amplitudes in the happyface condition. This suggests, although indirectly, increased response certainty with positive primes, a finding that the authors interpret within the cognitive tuning hypothesis, which postulates that people in a positive cognitive mode take decisions based on established routines and preexisting knowledge ${ }^{68}$ However, given the lack of increased response certainty at a behavioral level, the results of this study need to be interpreted with caution.

Yi investigated how ad affective context can influence perception of the ad, measured by variables such as brand evaluation, ad evaluation, and purchase decision. ${ }^{69}$ An advertisement emphasizing size of a car of a fictitious brand was used as the target; size was used as the main attribute because it can lead to positive (increased safety) or negative (increased fuel consumption) appraisals. These two attributes related to size were then primed by placing magazine articles before the target ad. To prime safety, an article about air travel was used, and to prime fuel consumption, a story about an oil industry entrepreneur was employed. Each of these stories was presented in two different affect conditions, one positive and one negative; affect manipulation was carried out by changing the tone of the story (for example, describing the dangers of air travel vs emphasizing increased safety in air travel). Participants were divided into four groups, according to theme and valence primed. Results indicated significant 
effects of theme and affective priming on the outcome variables, with more positive appraisal with positive theme or affective tone. However, a regression analysis suggested effects of affective priming on purchase decision were probably due to shared variance with effects on attitudes towards ad and brand. In any case, the main finding of the study was that evaluation of the ad was influenced by theme and affective tone of preceding articles, suggesting emotional context can impact on variables related to product evaluation, which in turn may affect future purchasing decision.

In a recent study, Cassotti et al explored whether emotional context influences financial decision-making. ${ }^{70}$ Specifically, the authors investigated changes in the "framing effect" according to exposure to emotional primes. The framing effect refers to the fact that alternatives that describe the same option in different formats lead to different decisions. ${ }^{47}$ Usually, a risk-averse choice is preferred when alternatives are phrased in terms of gain. ${ }^{71}$ In order to investigate the effect of emotion on framing, the authors divided participants into three groups: one primed with positive affective pictures, one with negative pictures, and one without any prime. Emotional pictures were taken from the International Affective Picture System ${ }^{72}$ and presented supraliminally for 5 seconds in each trial; nothing replaced the emotional primes in the no-prime condition. Immediately after exposure to the pictures, a decision-making task followed, in which participants received an initial amount of fake money and had to choose between a sure option (keeping part of the money) or a gamble option (losing or keeping the full money) in each trial. The sure option was framed either in terms of gain or loss, but always representing the same value. Results indicated that the group primed with positive pictures did not show a framing effect, ie, they chose the gamble option at the same frequency, irrespective of frame presentation. These findings have been interpreted by authors under a dual-processing framework, which suggests that decision-making is a combination of analytic (cognitive) and intuitive (affective) processes, the latter explaining the bias found in the framing effect. According to this framework, decisions based on affective content are fast and automatic, and it is possible that this process shares a similar neuroanatomical network with affective priming. Interestingly, framing effects have been associated with amygdala activation, and damage to the amygdala leads to decreased monetary-loss aversion. ${ }^{73,74}$ Accordingly, it is possible that in the reviewed study, positive-mood induction "offset" processing of negative emotion in the amygdala eliminated the "framing effect."

\section{Conclusion}

To summarize, we firstly demonstrated that priming, as an automatic and implicit processing of afferent data, can influence subsequent evaluation and judgment of target stimuli. In the second section, we showed that psychological factors indeed have a powerful effect in various types of purchase decision, and that merely axiomatic utility models insensible to psychological variables would not be able to explain some complex affective influences on decisional processes, featuring purchase decision. In the third section, we reviewed studies exploring the effectiveness of affective priming in decision-making, especially purchase decision. Although there are very few studies exploring this subject, preliminary evidence suggests a series of relevant effects of affective priming in purchase decisions. Deepening the exploration of such effects and confirming the scope of its effectiveness is a challenge for future research. Studies dealing with the costs and values of our real environmental contexts, and thus able to better model in laboratory settings our everyday context, would be welcome to raise the ecological validity of experiments in this field of research.

The influence of affective priming in purchase decisions can be understood within the framework proposed at the introduction of this article. Considering the fact that humans have their relationship with the environment oriented by processing of values, it is highly probable that exposure to affect-laden stimuli influences evaluative judgments and consequent behavior. The priming studies reviewed suggest that affective processing can be automatic and bypass consciousness, which may reflect the existence of parallel networks for processing similar information. More importantly, the influence of an affective prime on subsequent judgment/ behavior can occur without awareness of their causal relationship. Research in the field of social neuroscience ${ }^{75}$ suggests that affective stimuli shown in supraliminal mode are more likely to be controlled by higher cognitive functions, but that the same would not occur to the same extent in the case of subliminal stimuli. If we can assume similar mechanisms for affective priming, we have a complex and intricate horizon for the study of ethical implications of subliminal priming in purchase decision. To what extent would we have conscious control of subliminal primes in purchase decision? How could we regulate these techniques if our inability to control their influence was proven?

Considering the growing number of studies exploring the effects of affective priming on financial decisions, regulatory bodies and agencies must take notice of the 
results being produced by scientific experimental research. The legal cases reviewed in the introduction generated an important precedent in the US. Before the Vance vs Judas Priest judgment, in a pretrial motion, the judge stated that subliminal propaganda could not be protected by the First Amendment, because it is not able to promote any of the benefits elicited by free speech, such as dialogue, marketplace of ideas, or pursuit of truth, and that subliminal messages were a privacy invasion since they cannot be avoided. ${ }^{9}$ These statements were cited in the subsequent case (Wellar vs Osbourne), and still constitute the main source of case law, although the US does not have an explicit regulation of subliminal advertising, as in other countries. For example, in the UK, subliminal advertising is clearly and literally banned by rule 5.4 .5 ("Subliminal Advertising") of the Television Advertising Standards Code produced by the Broadcast Committee of Advertising Practice. ${ }^{76}$ According to the code, "no advertisement may use images of very brief duration, or any other technique which is likely to influence viewers, without their being fully aware of what has been done" (p 25). ${ }^{76}$ Rule 5.4.5 is part of the fifth section of the code dedicated to "Misleading Advertising," and at the same time, of subsection 5.4, "Creative Treatments," suggesting, somewhat ironically, that subliminal advertising is a creative form of misleading people into buying things without their being fully aware of the influences under which they are taking this course of action. Nevertheless, one important question remains unanswered: If an advertisement used a subliminal stimulus, how would an ethics committee perceive it? Examining frame by frame any advertisement film? Clearly, less expensive and time-consuming techniques need to be employed.

Beyond the simpler pragmatic issues above, we have to deal with deeper fundamental moral questions. Advertising has long been associating positive emotions with products, even in very counterintuitive cases, such as linking smoking with a "cool" lifestyle. The fact that some of these associations may be done subliminally raises a series of important ethical questions and challenges for the future.

\section{Acknowledgments}

We thank three anonymous reviewers for helpful comments on the first draft of this manuscript.

\section{Endnote}

*Throughout the text the term value is used, sometimes with different meanings. We refer to value mainly as biological value, the relevance that something has to the survival of the organism. This includes not only attribution of value to external objects but also to internal states. Within this framework, psychological value emerges from, but cannot be reduced to, biological value. Finally, in a few instances of the text we refer to economical value, in the sense of the axiomatic models of economics.

\section{Disclosure}

The authors report no conflicts of interest in this work.

\section{References}

1. Searle J. Minds, brains and programs. Behav Brain Sci. 1980;3:417-457.

2. Kahneman D. Maps of bounded rationality: a perspective on intuitive judgment and choice. Nobel Prize of Economics Lecture. December 8, 2002. Available from: http://www.nobelprize.org/nobel_ prizes/economics/laureates/2002/kahnemann-lecture.pdf. Accessed April 26, 2012.

3. Brean H. 'Hidden sell' technique is almost here: new subliminal gimmicks now offer blood, skulls, and popcorn to movie fans. Life. 1958;44: $102-114$.

4. Gafford R. The Operational Potential of Subliminal Perception. 1958. Available from: http://www.cia.gov/library/center-for-the-study-ofintelligence/kent-csi/vol2no2/html/v02i2a07p_0001.htm. Accessed April 26, 2012.

5. Danzig F. Subliminal advertising - today it's just historic flashback for researcher Vicary. Advertising Age. 1962;33:72-73.

6. Vicary JM, James M. Vicary Papers. University of Connecticut Repository. Available from: http://doddcenter.uconn.edu/asc/findaids/ Vicary/MSS19980320.html. Accessed April 26, 2012.

7. Packard V. The Hidden Persuaders. London: Penguin; 1960.

8. Rogers S. How a publicity blitz created the myth of subliminal advertising. Public Relations Quarterly. 1992;37:12-17.

9. Moore TE, American Psychology Law Society News. 1997;17(1):3-14. Scientific Consensus \& Expert Testimony: Lessons from the Judas Priest Trial. Available from: http://www.ap-ls.org/publications/newsletters/ spg97.pdf. Accessed August 2, 2012.

10. Schacter DL. Implicit knowledge: new perspectives on unconscious processes. Proc Natl Acad Sci U SA. 1992;89:11113-11117.

11. Weiskrantz L. Consciousness Lost and Found: A Neuropsychological Exploration. Oxford: Oxford University Press; 1997.

12. Fazio RH, Sanbonmatsu DM, Powell MC, Kardes FR. On the automatic activation of attitudes. J Pers Soc Psychol. 1986;50:229-238.

13. Baars BJ. In the theatre of consciousness: global workspace theory, a rigorous scientific theory of consciousness. J Conscious Stud. 1997;4: 292-309.

14. Grenwald AG, Draine SC, Abrams RL. Three cognitive markers of unconscious semantic activation. Science. 1996;273:1699-1702.

15. Hermans D, De Houwer J, Eelen P. The affective priming effect: automatic activation of evaluative information in memory. Cogn Emot. 1994;8:515-533.

16. Murphy ST, Zajonc RB. Affect, cognition, and awareness: affective priming with optimal and suboptimal stimulus exposures. J Pers Soc Psychol. 1993;64:723-739.

17. Yang J, Xu X, Du X, Shi C, Fang F. Effects of unconscious processing on implicit memory for fearful faces. PLoS One. 2011;6:e14641.

18. Baumgartner SE, Wirth W. Affective priming during the processing of news articles. Media Psychol. 2012;15:1-18.

19. Rohr M, Degner J, Wentura D. Masked emotional priming beyond global valence activations. Cogn Emot. 2012;26:224-244.

20. Neumann R, Lozo L. Priming the activation of fear and disgust: evidence for semantic processing. Emotion. 2012;12:223-228. 
21. Hermans D, Baeyens F, Eelen P. Odours as affective-processing context for word evaluation: a case of cross-modal affective priming. Cogn Emot. 1998;12:601-613.

22. Li W, Moallem I, Paller KA, Gottfried JA. Subliminal smells can guide social preferences. Psychol Sci. 2007;18:1044-1049.

23. Goerlich KS, Witteman J, Schiller NO, Van Heuven VJ, Aleman A, Martens S. The nature of affective priming in music and speech. $J \operatorname{Cogn}$ Neurosci. 2012;24:1725-1741.

24. Scherer LD, Larsen RJ. Cross-modal evaluative priming: emotional sounds influence the processing of emotion words. Emotion. 2011;11: 203-208.

25. Wyer NA, Calvini G. Don't sit so close to me: unconsciously elicited affect automatically provokes social avoidance. Emotion. 2011;11: $1230-1234$.

26. Fazio RH. On the automatic activation of associated evaluations: an overview. Cogn Emot. 2001;15:115-141.

27. Klauer KC. Affective priming. Eur Rev Soc Psychol. 1997;8:67-103.

28. Iida S, Nakao T, Ohira H. Prior cognitive activity implicitly modulates subsequent emotional responses to subliminally presented emotional stimuli. Cogn Affect Behav Neurosci. 2012;12:337-345.

29. De Houwer J, Hermans D, Eelen P. Affective and identity priming with episodically associated stimuli. Cogn Emot. 1998;12: 145-169.

30. Wittenbrink B, Judd CM, Park B. Evidence for racial prejudice at the implicit level and its relationship with questionnaire measures. J Pers Soc Psychol. 1997;72:262-274.

31. Dannlowski U, Ohrmann P, Bauer J, et al. Amygdala reactivity predicts automatic negative evaluations for facial emotions. Psychiatry Res. 2007;154:13-20.

32. Nomura M, Ohira H, Haneda K, et al. Functional association of the amygdala and ventral prefrontal cortex during cognitive evaluation of facial expressions primed by masked angry faces: an event-related fMRI study. Neuroimage. 2004;21:352-363.

33. Garolera M, Coppola R, Muñoz KE, et al. Amygdala activation in affective priming: a magnetoencephalogram study. Neuroreport. 2007; 18:1449-1453.

34. Rauch AV, Reker M, Ohrmann P, et al. Increased amygdala activation during automatic processing of facial emotion in schizophrenia. Psychiatry Res. 2010;182:200-206.

35. Liu H, Hu Z, Peng D, Yang Y, Li K. Common and segregated neural substrates for automatic conceptual and affective priming as revealed by event-related functional magnetic resonance imaging. Brain Lang. 2010;112:121-128.

36. Werheid K, Alpay G, Jentzsch I, Sommer W. Priming emotional facial expressions as evidenced by event-related brain potentials. Int $J$ Psychophysiol. 2005;55:209-219.

37. De Gelder B, Vroomen J, Pourtois G. Covert affective cognition and affective blindsight. In: De Gelder B, De Haan EHF, Heywood CA, editors. Out of Mind: Varieties of Unconscious Processes. New York: Oxford University Press; 2001:205-221.

38. Hamm AO, Weike AI, Schupp HT, Treig T, Dressel A, Kessler C. Affective blindsight: intact fear conditioning to a visual cue in a cortically blind patient. Brain. 2003;126:267-275.

39. De Gelder B, Hadjikhani N. Non-conscious recognition of emotional body language. Neuroreport. 2006;17:583-586.

40. LeDoux JE. The Emotional Brain: The Mysterious Underpinnings of Emotional Life. New York: Simon and Schuster; 1996.

41. Morris JS, Ohman A, Dolan RJ. A subcortical pathway to the right amygdala mediating "unseen" fear. Proc Natl Acad Sci U SA. 1999;96: $1680-1685$.

42. Mattavelli G, Cattaneo Z, Papagno C. Transcranial magnetic stimulation of medial prefrontal cortex modulates face expressions processing in a priming task. Neuropsychologia. 2011;49:992-998.

43. Rolls ET. The orbitofrontal cortex. Phil Trans R Soc Lond B Biol Sci. 1996;351:1433-1443.

44. Goldberg E, Podell K. Adaptive versus veridical decision-making, and the frontal lobes. Conscious Cogn. 1999;8:364-377.
45. Mograbi GJC. Neural basis of decision-making and assessment: issues on testability and philosophical relevance. Mens Sana Monogr. 2011;9:251-259.

46. Kahneman D, Tversky A. Prospect theory: an analysis of decision under risk. Econometrica. 1979;47:263-291.

47. Tversky A, Kahneman D. The framing of decisions and the psychology of choice. Science. 1981;211:453-458.

48. Prelec D, Loewenstein GF. The red and the black: mental accounting of savings and debt. Mark Sci. 1998;17:4-28.

49. Prelec D, Simester D. Always leave home without it: a further investigation of the credit-card effect on willingness to pay. Mark Lett. 2001;12:5-12.

50. Kuhnen CM, Knutson B. The neural basis of financial risk-taking. Neuron. 2005;47:763-770.

51. Knutson B, Rick S, Wimmer GE, Prelec D, Loewenstein G. Neural predictors of purchases. Neuron. 2007;53:147-156.

52. Knutson B, Adams CM, Fong GW, Hommer D. Anticipation of increasing monetary reward selectively recruits nucleus accumbens. J Neurosci. 2001;21:RC159.

53. Bechara A, Tranel D, Damasio H, Damasio AR. Failure to respond autonomically to anticipated future outcomes following damage to prefrontal cortex. Cereb Cortex. 1996;6:215-225.

54. Breiter HC, Aharon I, Kahneman D, Dale A, Shizgal P. Functional imaging of neural responses to expectancy and experience of monetary gains and losses. Neuron. 2001;30:619-639.

55. Martinez D, Slifstein M, Broft A, et al. Imaging human mesolimbic dopamine transmission with positron emission tomography. Part II: amphetamine-induced dopamine release in the functional subdivisions of the striatum. J Cereb Blood Flow Metab. 2003;23: 285-300.

56. Knutson B, Fong GW, Bennett SM, Adams CM, Hommer D. A region of mesial prefrontal cortex tracks monetarily rewarding outcomes: characterization with rapid event-related FMRI. Neuroimage. 2003; 18:263-272.

57. Knutson B, Taylor J, Kaufman M, Peterson R, Glover G. Distributed neural representation of expected value. J Neurosci. 2005;25: 4806-4812.

58. Bjork JM, Knutson B, Fong GW, Caggiano DM, Bennett SM, Hommer DW. Incentive-elicited brain activation in adolescents: similarities and differences from young adults. $J$ Neurosci. 2004;24:1793-1802.

59. Montague PR, King-Casas B, Cohen JD. Imaging valuation models in human choice. Annu Rev Neurosci. 2006;29:417-448.

60. Piech RM, Lewis J, Parkinson CH, et al. Neural correlates of affective influence on choice. Brain Cogn. 2009;72:282-288.

61. Paulus MP, Frank LR. Ventromedial prefrontal cortex activation is critical for preference judgments. Neuroreport. 2003;14:1311-1315.

62. Porcelli AJ, Delgado AR. Acute stress modulates risk taking in financial decision making. Psychol Sci. 2009;20:278-283.

63. Lerner JS, Gonzalez RM, Small DA, Fischhoff B. Effects of fear and anger on perceived risks of terrorism: a national field experiment. Psychol Sci. 2003;14:144-150.

64. Hsee CK, Rottenstreich Y. Music, pandas, and muggers: on the affective psychology of value. J Exp Psychol Gen. 2004;133:23-30.

65. Small DA, Loewenstein G, Slovic P. Sympathy and callousness: the impact of deliberative thought on donations to identifiable and statistical victims. Organ Behav Hum Decis Process. 2007;102: 143-153.

66. Steffen AC, Rockstroh B, Jansma B. Brain evoked potentials reflect how emotional faces influence our decision making. J Neurosci Psychol Econ. 2009;2:32-40.

67. Falkenstein M, Hoormann J, Hohnsbein J. ERP components in Go/Nogo tasks and their relation to inhibition. Acta Psychol (Amst). 1999;101: 267-291.

68. Schwarz N. Situated cognition and the wisdom in feelings: cognitive tuning. In: Barrett LF, Salovey P, editors. The Wisdom in Feeling: Psychological Processes in Emotional Intelligence. New York: Guilford; 2002:144-166. 
69. Yi Y. Cognitive and affective priming effects of the context for print advertisements. J Advert. 1990;2:40-48.

70. Cassotti M, Habib M, Poirel N, Aïte A, Houdé O, Moutier S. Positive emotional context eliminates the framing effect in decision-making. Emotion. Epub February 6, 2012.

71. Reyna VF. How people make decisions that involve risk: a dualprocesses approach. Curr Dir Psychol Sci. 2004;13:60-66.

72. Lang PJ, Bradley MM, Cuthbert BN. International affective picture system (IAPS): affective ratings of pictures and instruction manual. Technical Report A-6. Gainesville: University of Florida; 2005.

73. De Martino B, Kumaran D, Seymour B, Dolan RJ. Frames, biases, and rational decision-making in the human brain. Science. 2006;313:684-687.
74. De Martino B, Camerer C, Adolph R. Amygdala damage eliminates monetary loss aversion. Proc Natl Acad Sci U S A. 2010;107:3788-3792.

75. Cunningham WA, Johnson MK, Raye CL, Gatenby JC, Gore JC, Banaji MR. Separable neural components in the processing of black and white faces. Psychol Sci. 2004;15:806-813.

76. UK Broadcast Committee of Advertising Practice. Television Advertising Standards Code. Available from: http://www.bcap.org.uk/ TheCodes/ /media/Files/CAP/Codes/BCAPTVAdCode.ashx. Accessed August 2, 2012.

Neuroscience and Neuroeconomics

\section{Publish your work in this journal}

Neuroscience and Neuroeconomics is an international, peer-reviewed, open access journal focusing on the identification of brain structures and measurement of neural activity related to behavior, behavioral predictions, and decision making in health and disease. The manuscrip management system is completely online and includes a very quick and fair peer-review system. Visit http://www.dovepress.com/testimonials. php to read real quotes from published authors.

Submit your manuscript here: http://www.dovepress.com/neuroscience-and-neuroeconomics-journal 